\title{
Madinat al-Zahra, territorio y paisaje
}

Madinat al-Zahra fue fundada en el año 936 por orden del califa Abd al-Rahman III quien la ubicó en un emplazamiento único, un saliente de Sierra Morena que se asoma al valle del Guadalquivir, garantizando unas amplias vistas sobre la Vega y la Campiña cuyo alcance supera los $80 \mathrm{~km}$. Esta localización requirió de costosos trabajos de ingeniería y explanación que hubieran sido innecesarios en un emplazamiento de Ilanura, lo que implica que la topografía y el paisaje fueron determinantes en la elección del lugar.

Todo el territorio participó en el desarrollo de este inmenso proyecto urbano. La construcción de la ciudad, concebida como capital para el reconstruido califato omeya, trascendió sus límites amurallados y comportó la creación de nuevos asentamientos, de un complejo sistema de infraestructuras asociadas y de una importante red viaria para mantener la conexión, no sólo con Córdoba, sino con las principales ciudades de alAndalus. De esta forma, Madinat al-Zahra se convirtió en el centro articulador de un amplio territorio lindante con la propia ciudad de Córdoba, con la que compartió similares funciones urbanas.

Tras su destrucción a comienzos del s. XI y la amortización de una buena parte de sus infraestructuras, las sucesivas transformaciones históricas, como la construcción del monasterio de San Jerónimo en el s. XV y la instalación de las yeguadas reales de Castilla en tiempos de Felipe II, han terminado por conformar uno de los conjuntos patrimoniales más importantes y cualificados de Europa, y un extraordinario paisaje cultural. Su preservación ha constituido uno de los objetivos de la Consejería de Cultura a través del Plan Especial de protección de Madinat al-Zahra, porque este paisaje conserva gran parte del ordenamiento original creado por la ciudad, lo que posibilita la programación de un conjunto de actividades que nos acerquen al conocimiento y disfrute de sus valiosos recursos culturales y naturales. Valga como ejemplo el programa de recorridos temáticos guiados por los distintos elementos del territorio, iniciado en el año 2007, y que complementa otros realizados en el interior de la ciudad.

La apuesta de Madinat al-Zahra no puede ser otra que la de recomponer, recuperar y poner en valor el conjunto de relaciones territoriales y culturales que han conformado este excepcional paisaje. Y, sobre todo, poder desarrollar sus extraordinarias potencialidades y recursos de todo tipo, desde la recuperación de los itinerarios de acceso originales que permitan comprender la auténtica significación del monumento, hasta la puesta en valor de las canteras de donde se extrajo el material pétreo para la construcción, los recorridos por el trazado de la infraestructura hidráulica a través de unos parajes serranos de un gran valor natural, o la instalación de miradores desde donde educar en los valores y singularidades de este excepcional modelo de paisaje mediterráneo. El desarrollo de estas potencialidades debe verse no sólo en clave de una absoluta necesidad para Madinat alZahra, sino también de una extraordinaria oportunidad para Andalucía y para su desarrollo cultural, económico, turístico y ambiental.

La próxima apertura del nuevo museo de Madinat al-Zahra (ver sección Actuaciones de este número) va a suponer un renovado impulso en este proceso. Con esta infraestructura, diseñada con unos criterios de respeto absoluto al paisaje, vamos a explicar uno de estos recursos, el más valioso, la imponente estructura urbana creada en el s. X, y con ello vamos a dotar de calidad y significación a la visita al yacimiento y al territorio.

Para desarrollar el resto de las potencialidades y hacer frente a las amenazas del urbanismo ilegal generado a partir del año 1995 , se hace necesario producir una nueva transformación cultural de este paisaje, porque el dilema que se plantea en estos momentos es si el territorio de Madinat al-Zahra debe consolidar una vocación y una dedicación cultural al servicio de un modelo de recuperación social y científico o si, por el contrario, va a convertirse en una prolongación urbanística de la propia ciudad de Córdoba. 
( Vista de Madinat al-Zahra desde el sur / JOSÉ MORóN

- Gran Pórtico del palacio / Isabel Duco, IAPH

( Canteras de La Aljabilla / MAnuel PIJuÁN
(1) Vista de la mezquita de Madinat al-Zahra / ISABEL Dugo, IAPH

- Arcos restaurados del Puente de los

( Vista aérea del nuevo museo y su relación con Madinat al-Zahra ang

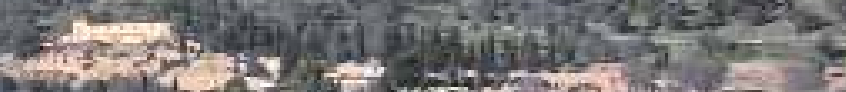

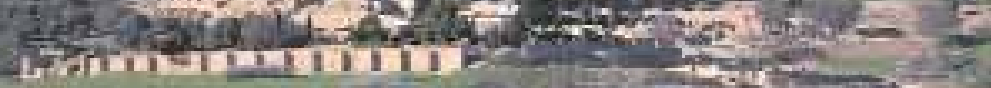

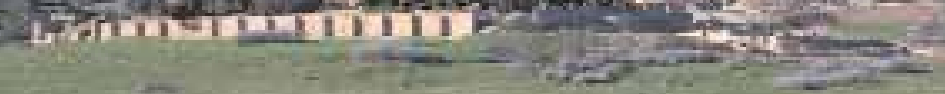

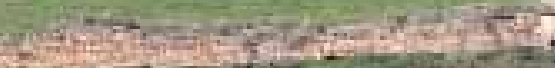

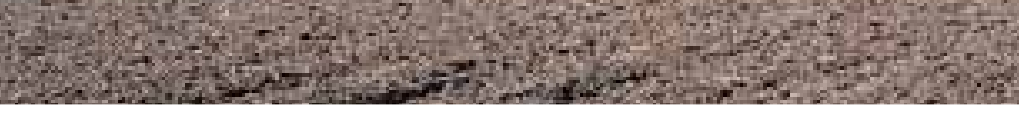

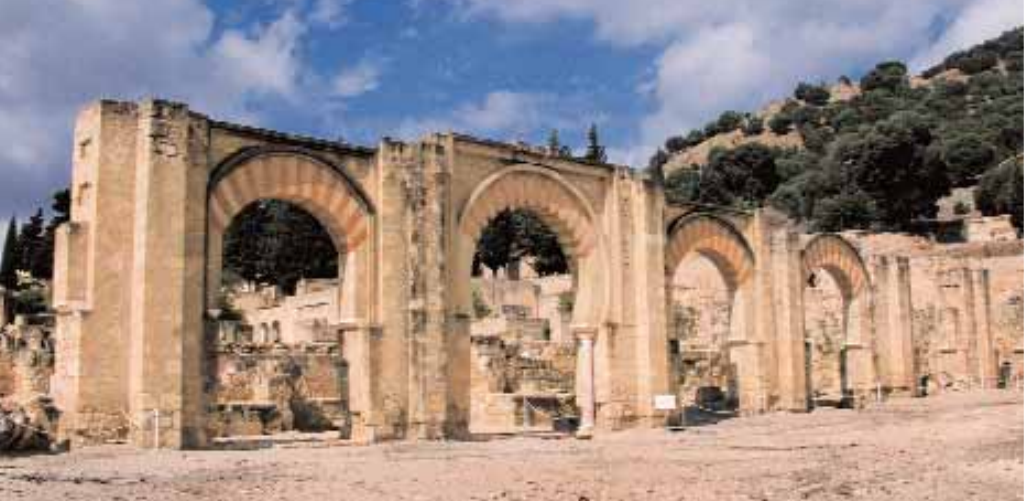

avestat-

74 is:

- 9.

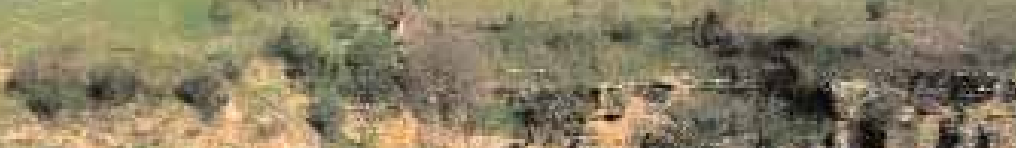

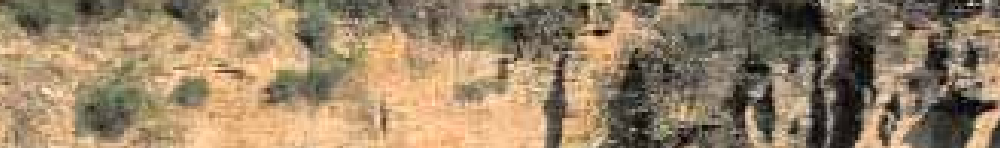

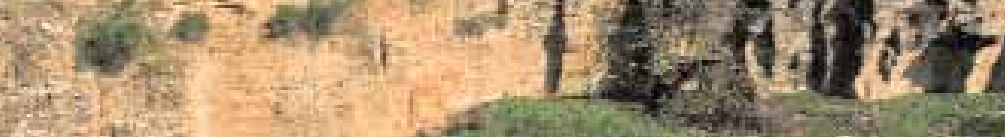
t.

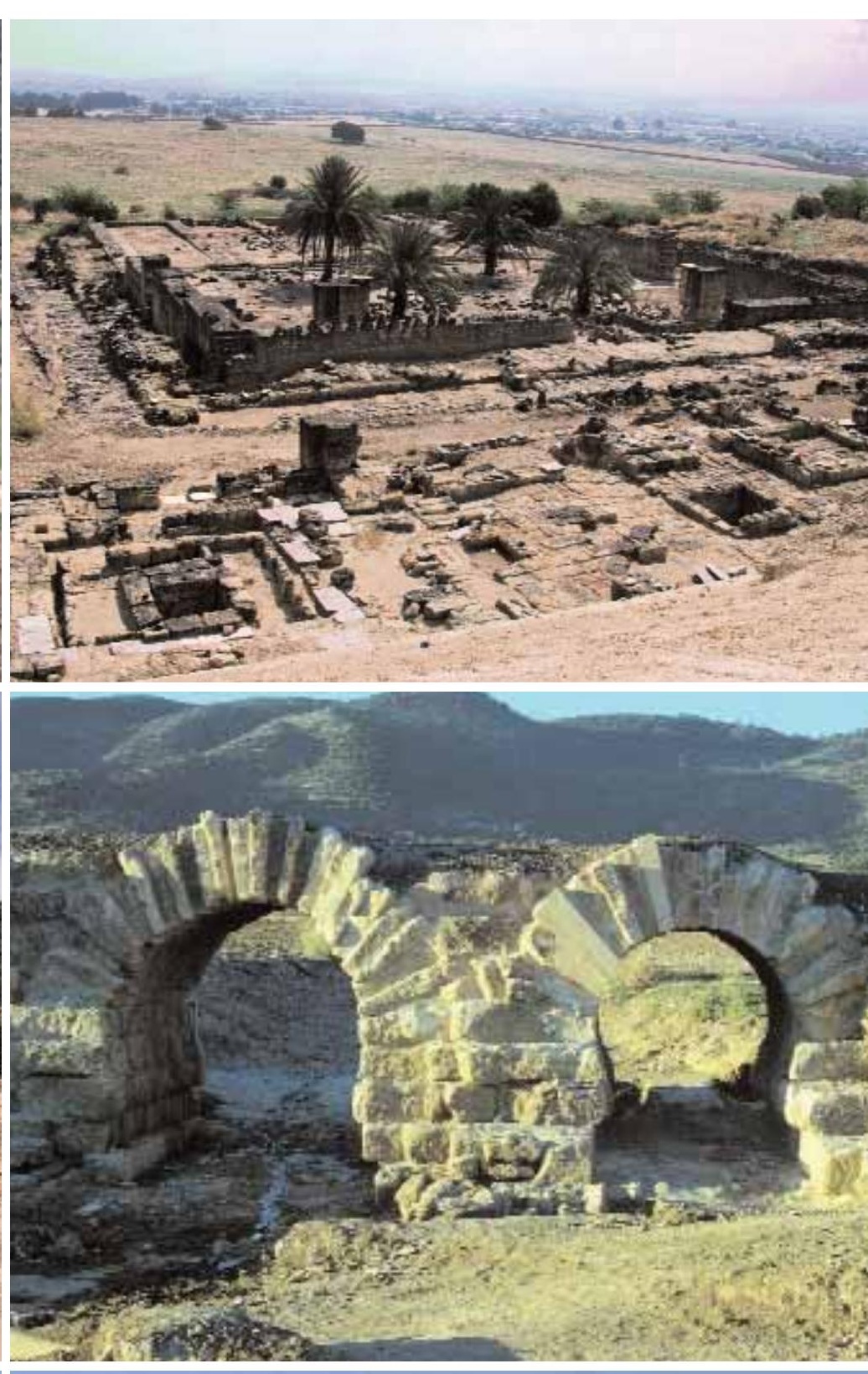

